\title{
Informational Nudges to Encourage Pro-environmental Behavior: Examining Differences in Message Framing and Human Interaction
}

\section{OPEN ACCESS}

Edited by:

Irena Knezevic,

Carleton University, Canada

Reviewed by:

Emma Frances Bloomfield,

University of Nevada, Las Vegas,

United States

Arren Mendezona Allegretti,

Santa Clara University, United States

${ }^{*}$ Correspondence:

Katherine Nelson opelikakatie@gmail.com

Specialty section:

This article was submitted to Science and Environmental

Communication,

a section of the journal

Frontiers in Communication

Received: 25 September 2020 Accepted: 18 December 2020

Published: 09 February 2021

Citation:

Nelson KM, Bauer MK and Partelow S (2021) Informational Nudges to

Encourage Pro-environmental Behavior: Examining Differences in

Message Framing and

Human Interaction.

Front. Commun. 5:610186.

doi: $10.3389 /$ fcomm.2020.610186

\author{
Katherine M. Nelson ${ }^{1 *}$, Mirja Kristina Bauer ${ }^{2}$ and Stefan Partelow ${ }^{1}$ \\ ${ }^{1}$ Leibniz Centre for Tropical Marine Research, Bremen, Germany, ${ }^{2}$ Department of Biology/Chemistry, University of Bremen, \\ Bremen, Germany
}

Two natural field experiments were implemented to examine the influence of framing effects on environmental behavior. The first study examined plastic bag use at a convenience store using low cost nudges: an informational message on a sign and interpersonal communication at check-out. We employed a $3 \times 2$ treatment design (positive message vs. negative message vs. no sign; each paired with both asking for bag vs. not asking for bag) and report the observed plastic bag use behavior. A second study was conducted using a pre-snorkel briefing with two message frames-positive, negative, and no briefing (control). Environmentally damaging snorkel behavior was anonymously observed and recorded. Both experiments show the same general result: a significant and positive difference between subjects that were exposed to an intervention compared to those in the control conditions. However, we do not find significant differences in observed environmental behavior between the negative and positive framing.

Keywords: environmental communication, behavioral experiment, natural field experiment, nudges, environment, conservation

\section{INTRODUCTION}

Ecosystems and natural resources are humankind's basis of life, but are generally facing pollution, degradation and overexploitation (Dwyer et al., 1993; Osbaldiston and Schott, 2012). The decreasing environmental quality mostly originates from anthropogenic influences, a consequence of human behavior (Dwyer et al., 1993; Steg and Vlek, 2009). The social-ecological systems literature has focused extensively on framing and analyzing these interdependent relationships between societies and the environment (Colding and Barthel, 2019; Vos et al., 2020). In tourism, human-environment relationships are co-shaped by the context (Scott et al., 2012). For example, willingness to use a reusable bag can be influenced by who sends the message, which has impacts on local environmental pollution (Spranz et al., 2018). Similarly, the problems a tourist recognizes as important are linked to their cultural salience and local visibility. Beach trash is more noticeable then underground sewage leakages or invisible contaminants from plastics and sunscreen on reefs, and thus beach clean ups and macro-pollution mitigation measures are often put forth as solutions (Brouwer et al., 2017). These features shape tourist, business owner and environmental governance actor perceptions about how to prioritize environmental problems and what can be done to govern human behavior to solve them (Scott et al., 2012). 
Large-scale changes of human behavior are crucial to diminish the underlying drivers of environmental problems and to better structure institutions (i.e., rules and norms) that provide the incentives for individuals to act in ways that do not undermine pro-environmental goals of society as a whole (Dwyer et al., 1993; Steg and Vlek, 2009). To achieve this goal, there are many possible approaches such as international agreements, governmental policies, technological innovations, educational programs or market-driven changes. Individual behavior change is often voluntary and is triggered by the social market based on reflecting one's image and reputation to peers.

Nudges are low-cost interventions that influence decisionmaking without limiting freedom of choice and have been tested in the environmental realm of electricity and water saving, reduced meat consumption, recycling, and decreasing private car transportation (Kollmuss and Agyeman, 2002; Cheng et al., 2011; Osbaldiston and Schott, 2012). Sunstein (2014) notes that nudging refers to "liberty-preserving approaches that steer people in particular directions, but that also allow them to go their own way" (p. 583), and that nudges "are specifically designed to preserve full freedom of choice" (p. 584). The benefits of nudging approaches include their typical low costs, preservation of individual choice, and ability to achieve desired outcomes without large systemic changes. They are often low cost because a lot of nudging is about how information is presented and organized, often referred to as altering the 'choice architecture' available to individuals, which is always there, but often not consciously designed. It preserves individual freedom of choice because there is no coercion, but rather information messaging or choice options are presented transparently in different ways. Finally, nudging does not often require systemic changes, for example changing the policy structure of the entire health care system, but rather influencing how individuals make choices within it to optimize desired outcomes.

The purpose of this paper is to observe real behavior changes using natural field experiments with different types of proenvironmental communication framing interventions, and to test the effectiveness of those framing intervention nudges. Due to the disparate and largely inconclusive literature on the topic in the environmental realm, this study aims to add clarity with findings from two experiments on different environmental problems 1) plastic pollution and 2) coral reef degradation on Gili Trawangan, Indonesia. The findings of these two studies contribute to the framing and environmental behavior literature and can inform design of future research, but also demonstrate practical intervention strategies for influencing human behavior in relation to local environmental management.

According to the Theory of Planned Behavior, proenvironmental behavior is thought to be influenced by one's environmental knowledge, attitudes, social pressures, values and beliefs (Kollmuss and Agyeman, 2002). Environmental attitudes are an often-studied component of behavioral intentions, and, less so, of actual observed behavior (Heimlich and Ardoin, 2008). Correlations between attitudes and actual behavior have been proven to be weak (Kollmuss and Agyeman, 2002; Masud et al., 2015; Nelson et al., 2020). Additionally, the type of informational framing is thought to influence decisions but the success of the frame is dependent not only on what is said, but how it's said at specific points of a person's decision stage (i.e., early stage of determining whether an issue is problematic based on its personal risk/costs or the later stage of establishing intention to act) (Entman, 1993; Cheng et al., 2011). Therefore, targeting interventions to different audiences is necessary and to do so, a distinction between antecedent and consequence strategies has been made: Antecedent strategies are aimed to change the factors that precede the behavior, e.g., informing about choice options, raising awareness or prompting. By comparison, consequence strategies are aimed to change the consequences following a behavior, e.g., penalties, rewards or feedback (Steg and Vlek, 2009).

Although a multitude of studies have used interpersonal communication to examine environmental behaviors (for a review see Osbaldiston and Schott 2012), few of these studies compare observed behavior between printed media and face-toface interactions. One study showed that in antecedent behavioral interventions, based on giving information in advance, personal interaction is more effective compared to only presenting information in a non-interactive way (e.g., print, digital). Curbside recycling was increased by personal communication rather than by printed persuasive communication alone (Burn, 1991) and lawn watering was decreased when students were talking to residents compared to the 'information only' treatment (McKenzie-Mohr, 2000). A reason for this may result from the desire for social recognition and approval which acts as a motivator for performing a specific behavior (Cook and Berrenberg, 1981).

Nevertheless, a cross-cultural phenomenon called 'knowledgeaction' gap occurs. Hundreds of studies have failed to explain the gap between environmental knowledge held by individuals and the resulting pro-environmental behavior they exhibit (Kollmuss and Agyeman, 2002). Consequently, while the type and availability of information should continue to be studied, how this information is being communicated also needs to be further examined (Kennedy et al., 2009; Cheng et al., 2011). This includes the framing of how information is communicated both verbally and visually (Nelson et al., 2019; Nelson et al., 2020).

\section{Framing Effects}

The framing effect, resulting from message or valence framing, is described as a cognitive bias emerging from the way information is communicated or presented (Entman, 1993; Plous, 1993; Levin et al., 1998; Avineri and Waygood, 2013). Although the "Classic Economic Theory of Rational Choice" concludes that individuals base their choices only on the content of the information and not in the way it is presented, "Prospect Theory" states that the kind of framing can influence decision making and behavior differently (Kahneman and Tversky, 1979). Prospect theory posits that decision making can be altered by the potential perceived losses (loss frame) or perceived gains (gain frame) from a specific reference point with which information is presented (e.g., 10\% lives lost vs. 90\% lives saved) (Kahneman and Tversky, 1979; Tversky and Kahneman, 1992; Avineri and Waygood, 2013). 
Research has shown that communicating a descriptive norm that gives people cues about expected behavior (or inappropriate behavior) through written information can induce conformity (Schultz, 1999; Nolan et al., 2008). Although much research has been done in the field of framing in various contexts such as politics, consumer behavior, health or environmental communication, many contradictory results exist and the answer to which framing (e.g., positive or negative) leads to more behavior change in a specific context is not consistent (Entman, 1993; Levin et al., 1998; Piñon and Gambara, 2005; Entman et al., 2009; Spence and Pidgeon, 2010; Cheng et al., 2011; Kim and Kim, 2014; Baxter and Gram-Hanssen, 2016). For instance, in a study where the benefits of performing climate change mitigating behaviors were highlighted, subjects reported higher average positive environmental attitudes in comparison to the frame focusing on the risks and threats of refraining from mitigation behaviors (Spence and Pidgeon, 2010; Maibach et al., 2014). Nonetheless, as stated previously, there is weak evidence, at best, that attitudes and intentions (e.g., knowledge) translate into actual behavior, and more research is needed in different contexts.

For example, in a virtual reality-based intervention, it was tested whether gain or loss framing was more influential in provoking respondents to be willing to donate money and time for biodiversity conservation organizations (Nelson et al., 2020). The authors found that the negatively framed audio together with $360^{\circ}$ virtual reality video resulted in more money donated, but only in the context of tourists that were immediately impacted by the health of the natural resource-which in this case happened to be coral reefs. Respondents' behavioral attitudes were not a significant indicator for their behavior (Nelson et al., 2020). Ahn et al. (2015) conducted a virtual experiment with a visual framing (instead of semantic framing) in which subjects were exposed to either cutting (negative) or planting (positive) a tree in an animation. Overall, the virtual experience (regardless of negative or positive frame) resulted in higher intentions of purchasing recycling paper compared to the control (only text). This experiment only measured reported behavior and intentions and was conducted in a laboratory which may have resulted in a difference to real-world behavior (Levitt and List, 2007).

Surprisingly, to the authors' knowledge, only one proenvironmental framing experiment has been implemented as a natural field experiment using observable behavior (White et al., 2011). White et al. (2011) show that the mind-set of the message played a role in a recycling study: negative frames led to more recycling with a concrete mind-set (how should be recycled) and positive frames led to more recycling with an abstract mind-set (why should be recycled) (White et al., 2011). Although actual recycling behavior was measured, the framing itself was not tested on its own, but together with the induced mind-set message. They conclude that framing effectiveness is highly context dependent and they do not offer general recommendations favoring positive or negative framing to enhance pro-environmental behavior change interventions.

\section{Study Location and Context}

The Gili islands-Gili Trawangan, Gili Meno and Gili Air-are small tropical islands off the northwest coast of Lombok, located in the strait between Lombok and Bali, Indonesia. Gili Trawangan is the largest of the three islands, at approximately six square kilometers. The population consists of around 2000 people, mainly Indonesians, but also western expatriates (Hampton and Hampton, 2008; Willmott and Graci, 2012; Halim, 2017). Gili Trawangan is the furthest developed and most frequently visited of the Gili islands with an estimate of well over a million visitors annually (Partelow and Nelson, 2018). Gili Trawangan is highly dependent on tourism, particularly marine tourism as it is the second most popular destination in South East Asia for SCUBA certification (Partelow and Nelson, 2018). Overcapacity and degradation of natural resources from pollution (i.e., challenges with waste management) and tourism are rapidly becoming a problem. This includes a lack of freshwater, insufficient solid waste and sewage treatment, plastic pollution, reef degradation, beach erosion due to coastal construction, and illegal fishing and anchoring (Bachtiar, 2000; Hampton and Hampton, 2008; Willmott and Graci, 2012; Graci, 2013).

On Gili Trawangan, waste collection volumes range from 10-15 tons per day during high season and 3-5 tons per day in low season of which $42 \%$ is non-organic waste (Cannucciari and Martiana, 2016). All non-recyclable waste stays on the island and is brought to the landfill. Burning of waste is typical and it is common to see waste dumping sites scattered around the island and eventually ending up in the ocean.

Regarding the marine environmental problems, coral reef degradation is one of the most severe ones. As a result, the local non-governmental organization Gili Eco Trust was established in 2002 with the aim to conserve the coral reefs. Scuba diving and snorkeling can immensely deteriorate the health of coral reefs, mainly from physically touching the reef whether accidently or purposefully (Barker and Roberts, 2004; Hannak et al., 2011). Scuba divers as well as snorkelers were reported to physically damage corals and harass marine wildlife (Barker and Roberts, 2004). Although the impact of touching corals might not be obvious, it can adversely affect the coral's physiological condition, especially repeated occurrence by millions of snorkelers and divers visiting the island annually (Barker and Roberts, 2004). By disturbing the thin mucous layer the susceptibility for diseases and algal overgrowth can increase (Morrow et al., 2011). It is evident that even minimal impacts caused by divers can result in irreversible damage, of which the extent of these affects is cumulative in high traffic areas, such as on Gili Trawangan (Krieger and Chadwick, 2013).

As snorkeling and diving are the main tourist activities on Gili Trawangan, exploring management interventions that could minimize their impacts should be considered. Already in 1997, Hampton and Hampton (2008) found signs of damage caused by snorkelers on the reefs of Gili Trawangan. Most damage resulted from snorkelers walking or standing on corals, or bumping into them while snorkeling (Hampton and Hampton, 2008). With increasing tourist volume, pressure on the coral reefs is also increasing, threatening the health of coastal ecosystems and the viability of tourism as form of sustainable development for the island's economy. 

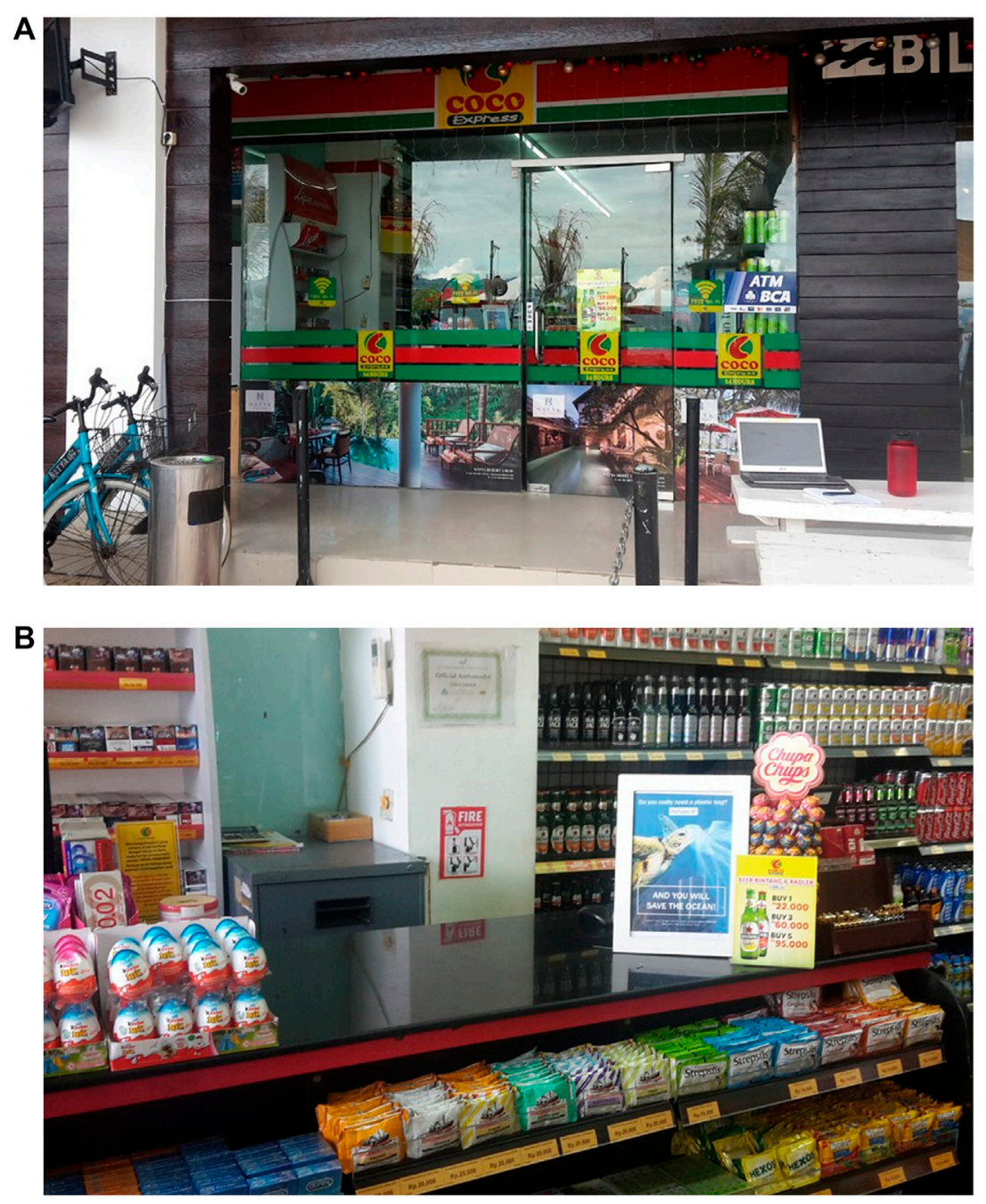

FIGURE 1 | (A) (top): The seating area in front of the Coco Express store with window fronts. (B) (bottom): Positive message sign on the counter of the Coco Express store.

\section{EXPERIMENT 1: PLASTIC BAG INTERVENTION}

The amount of plastic pollution ending up in the world's oceans is increasing (Jambeck et al., 2015; PEMRG, 2018). Plastic pollution harms marine wildlife, such as turtles, whales and sea birds because they confuse it with nutritious food. Indonesia is the second biggest contributor to marine plastic pollution with an estimated input of $0.48-1.29$ million metric tons each year (Jambeck et al., 2015). Plastic bags in Indonesia are commonly provided for free, often with every purchase, regardless of the size or quantity of items. In this study, we introduce different verbal and visual treatments as framing interventions to discourage the use of plastic bags at a convenience store on Gili Trawangan.

\section{Methods}

The study location was a convenience store called Coco Express, a retail chain. This was chosen because it is one of the two most common and busiest shops on Gili Trawangan. The location was at the south end of the main beachfront strip frequented heavily by tourists. The sitting area in front of the shop (bottom-right in Figure 1A) allowed for anonymous observation of consumer purchases (Figure 1A) and facilitated the follow-up questionnaire of each customer upon exit.

A $3 \times 2$ full factorial between-subject's experimental design was implemented to observe differences in behavior. The first factor is message framing with three levels: positive, negative and a control with no sign. The second factor refers to whether the shop assistant asks the customer if he/she needs a plastic bag (asking) ("Do you need a plastic bag?") or places the purchased items in a plastic bag without asking unless the customer actively refuses a plastic bag (not asking). A total of 721 observations were included for analysis (see Table $\mathbf{1}$ for sample sizes by treatment).

The treatments were displayed as an informational sign on the check-out counter of the shop (Figure 1B). The positively framed message was: "Do you really need a plastic bag? Refuse it and you 
TABLE 1 | Sample size by treatment allocation.

\begin{tabular}{|c|c|c|c|c|}
\hline & Positive framing & Negative framing & Control (no poster) & Total \\
\hline Asking & Treatment1 (T1) N = 124 & Treatment2 (T2) N = 118 & Treatment3 (T3) $\mathrm{N}=124$ & $N=366$ \\
\hline Not asking & Treatment4 (T4) N = 119 & Treatment5 (T5) $\mathrm{N}=114$ & Treatment6 (T6) N = 122 & $N=355$ \\
\hline Total & $N=243$ & $N=232$ & $N=246$ & $N=721$ \\
\hline
\end{tabular}

A

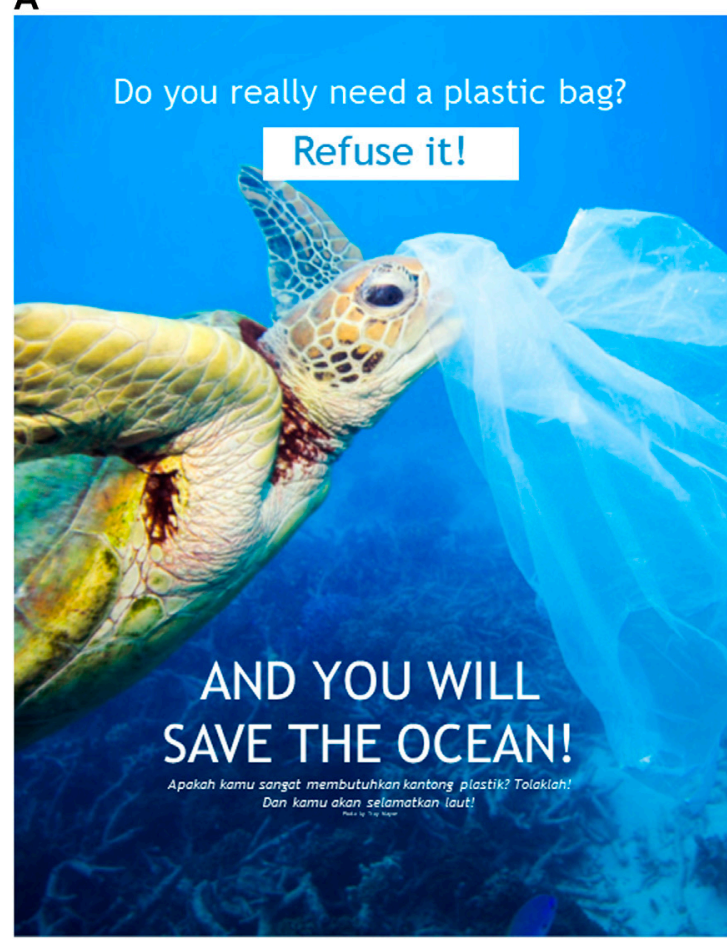

B

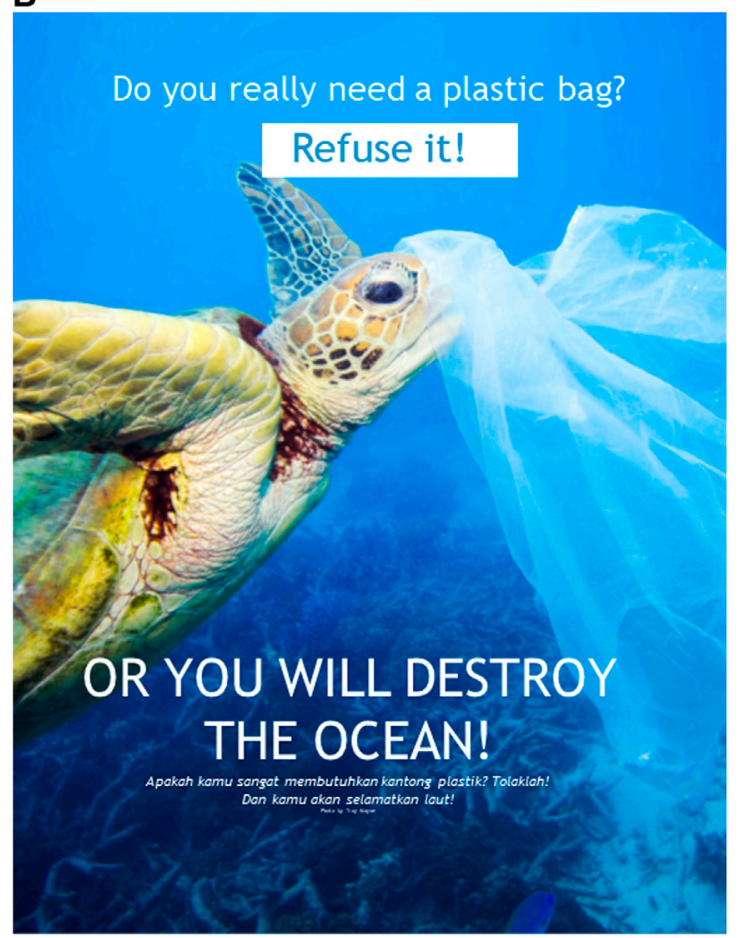

FIGURE 2 | Positively (left) and negatively (right) framed signs that were placed on the store's counter.

will save the ocean!" and the negatively framed message read: "Do you really need a plastic bag? Refuse it or you will destroy the ocean!" (see Figure 2). The message was in English as the target audience was foreign tourists and it was also translated into Indonesian (Bahasa Indonesia) and printed in smaller font below the English text.

A structured survey was created to collect personal data and supplement the interpretation of the observed behavioral intervention experiments on each subject as they exited the shop, including questions on socio-demographics, income, activities on the island, perceptions on plastic pollution on Gili Trawangan, pro-environmental behavior intentions and actions already performed on the island (see Appendix I). The research was approved by the institutional ethical review committee for Leibniz ZMT, and was conducted in accordance with the ethical standards of the German Data Protection Act, and the 1964 Helsinki Declaration and later amendments. Informed consent was obtained from all individual participants that filled out the survey. Given the large mix of nationalities and difficulty standardizing income with purchasing power parity across so many different contexts, participants were asked for the cost of their hotel per night as a proxy to income, in addition to their selfassessment of income status relative to others in their home country.

From 2:00-8:00 pm was chosen for observations as this was the busiest time. To randomize observation times and days, each treatment was set to a period of $2 \mathrm{~h}$ with $5 \mathrm{~min}$ in between. The random assignment of treatments to observation times was done with $\mathrm{R}$ Studio (Package: Base) using the function sort() and order(). The target minimum sample size per treatment was 100. Interventions and observations took place on 19 days between November 14, 2018 and December 17, 2018.

Before a treatment was implemented, shop assistants were briefed about their verbal cues (asking/not asking) using Google Translate to ensure proper understanding and adherence to the treatment. The customers were observed through the glass window of the shop and the following information was recorded: gender (male or female), single item purchased, number of small items 


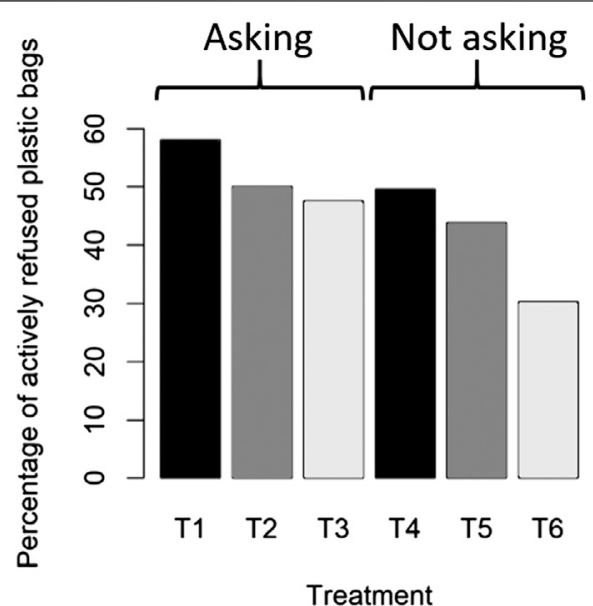

Treatment
$\mathrm{T} 1$ : positive and asking

T2: negative and asking

T3:nosignandasking

T4: positive and not asking

T5: negative and not asking

T6:nosignand notasking

Positive framing

Negative framing

No sign/ no framing

FIGURE 3 | Percentage of actively refused plastic bags per treatment including the treatment description.

purchased (defined as items that fit in a trouser pocket/small hand bag), number of large items purchased (items that do not fit into a trouser pocket/small hand bag), and whether the customer took a plastic bag. Single items were items that are consumed right after the purchase, for example ice cream, hot beverages, beverages that were opened in the shop or right after leaving the shop. The customers that bought a single item were recorded $(N=602)$, but later they were excluded from the analysis because no bag was necessary since these items were immediately consumed, and their inclusion may bias the effect of the intervention (Total $\mathrm{N}=1,323-602$ dropped $=721$ ).

After the customer's behavior had been observed and upon exiting the store they were approached and asked whether they would have time for a three-minute survey about plastic pollution on Gili Trawangan. When a couple or a group of persons bought items together, the behavior of the one who paid was observed as he/she was in the position to make a decision about taking a plastic bag or refusing it. Consequently, only this person was asked to fill in the survey.

\begin{tabular}{|c|c|c|}
\hline Comparison & Treatments & $p$-value (Effect size) \\
\hline \multirow[t]{2}{*}{...Between positive and negative framings } & $\mathrm{T} 1{ }^{*} \mathrm{~T} 2$ & $0.259(0.16)$ \\
\hline & $\mathrm{T} 44^{\star} \mathrm{T} 5$ & $0.457(0.11)$ \\
\hline \multirow[t]{3}{*}{...Between asking/not asking } & $\mathrm{T} 11^{\star} \mathrm{T} 4$ & $0.231(0.17)$ \\
\hline & $\mathrm{T} 2 * \mathrm{~T} 5$ & $0.421(0.12)$ \\
\hline & $\mathrm{T} 3^{\star} \mathrm{T} 6$ & $0.008^{\star \star}(0.36)$ \\
\hline \multirow[t]{2}{*}{...With control for sign } & $\mathrm{T} 1{ }^{\star} \mathrm{T} 3$ & $0.127(0.21)$ \\
\hline & $\mathrm{T} 2 *$ T3 & $0.804(0.05)$ \\
\hline \multirow{4}{*}{$\begin{array}{l}\text {..With control for sign and asking/not } \\
\text { asking }\end{array}$} & $\mathrm{T} 1{ }^{\star} \mathrm{T} 6$ & $<0.001^{\star \star \star}(0.57)$ \\
\hline & $\mathrm{T} 22^{\star} \mathrm{T} 6$ & $0.003^{\star \star}(0.40)$ \\
\hline & $\mathrm{T} 44^{\star} \mathrm{T} 6$ & $0.003^{* \star}(0.40)$ \\
\hline & $\mathrm{T} 5^{\star} \mathrm{T} 6$ & $0.044 *(0.28)$ \\
\hline
\end{tabular}

${ }^{*}, * *,{ }^{* * *}$ indicates significance levels at the $\mathrm{p}<0.05,0.01$, and 0.001 levels, respectively.

\section{Results of Experiment 1}

Of the 721 people observed, 319 were women and 402 were men. On average, $3.32 \pm 1.85$ items were purchased per subject, whereby the number of small purchased items is $0.43 \pm 0.73$ and the number of large purchased items is $2.89 \pm 1.77$. From the total sample, an average of $46.60 \%$ of the subjects actively refused to take a plastic bag.

The largest proportion of people who actively refused plastic bags were found under T1 (positive and asking) with 58.06\% and the lowest proportion of people who refused plastic bags were exposed to T6 (no sign and not asking) with 30.03\%. The percentage of actively refused plastic bags per treatment is presented in Figure 3.

Although the proportion of people refusing plastic bags was higher in the treatments with the positive framing, suggesting a trend, the two-sided proportion test revealed no significant differences between the positive and negative framing (see Table 2).

The interaction factor (asking/not asking) only showed significant differences between treatment 3 and $6(p=0.008)$, which were the treatments without a sign. Compared to the control for no sign/not asking (T6) and all treatments with a sign, there are significantly higher proportions of refused plastic bags in all sign treatment conditions (see Table 2).

The logistic stepwise regression (Table 3) revealed that the numbers of small and large items are both highly positively related to the acceptance of a plastic bag (both: $p<0.001$ ). Consequently, the probability of accepting a plastic bag is increasing with the number of purchased items (small or large). Similarly, subjects exposed to the treatment $5(p=0.048)$ and treatment $6(p<0.001)$ are more likely to obtain a plastic bag.

Of the 201 subjects who filled in the survey, 53.7\% stated their gender as female, $44.8 \%$ as male and $1.5 \%$ as other. The age of the survey participants ranged from 17 to 71 , with a median of 27 . The observed behavior of survey respondents differs from the overall observed behavior: only $40.80 \%$ of the survey respondents 
TABLE 3 | Regression results for accepted plastic bags (observation data).

\begin{tabular}{|c|c|}
\hline Time 2 (4:05-6:05 pm) & $0.145(0.269)$ \\
\hline Time 3 (6:10-8:10 pm) & $0.486(0.259)$ \\
\hline Treatment 2 & $0.190(0.317)$ \\
\hline Treatment 3 & 0.009 (0.327) \\
\hline Treatment 4 & $0.272(0.339)$ \\
\hline Treatment 5 & $0.697^{*}(0.352)$ \\
\hline Treatment 6 & $1.204^{\star \star \star}(0.327$ \\
\hline Number of small items & $0.472^{\star \star \star}(0.138$ \\
\hline Number of large items & $0.682^{\star \star \star}(0.079$ \\
\hline Pseudo R-squared (Mc Fadden) & 0.164 \\
\hline No. observations & 721 \\
\hline
\end{tabular}

Standard errors are reported in parentheses.

*, **, *** indicates significance levels at the $\mathrm{p}<0.05,0.01$, and 0.001 levels, respectively.

actively refused plastic bags. Responses on statements about observation of plastic pollution on Gili Trawangan, concern about pollution, self-efficacy and contribution to it are summarized in Table 4.

Survey results suggest strong agreement that a plastic pollution problem exists and agree is negative, but also that subjects could do something about it (93\%) (Table 4). In contrast, the most effective treatment (T1) shows less than $60 \%$ take an individual action (i.e., refused bag). This indicates a knowledge-action gap. More specifically, survey respondents that stated they paid a higher price for their accommodation were significantly more likely to accept a plastic bag $(p=0.039)$. Concern about the environmental consequences of plastic pollution on Gili Trawangan increased the probability of accepting a plastic bag $(p=0.038)$ which appears contradictory but also demonstrates the knowledge-action gap. Together, the sum of all proenvironmental behaviors performed on Gili Trawangan was significant $(p=0.003)$ and negatively correlated to the probability of subjects accepting a plastic bag.

Overall, all treatments were significantly more effective in discouraging the use of plastic bags compared to the control treatment (T6-no sign and not asking). Although no framing effect was detected, the treatment T1-positive and asking resulted in the largest proportion of actively refused plastic bags and the probability of people actively refusing a plastic bag is significantly higher compared to the control treatment (T6-no sign and not asking). The interaction (asking whether a plastic bag is needed) is especially important when there is no sign. However, a sign discouraging the use of plastic bags is helpful as a low-cost and low-effort approach to reduce plastic bag use, even if it serves only as a reminder to the clerk to ask each customer if they need a bag.
Despite the significant difference between treatment 5 (negative framing and not asking) and treatment 6 (no sign and not asking) resulting from the proportion test, the logistic regression indicates that both treatments cause a higher probability of people accepting a plastic bag. Consequently, when no interaction with customers is possible (i.e., through self-checkout lanes), a positively framed visual message is advisable to reduce the consumption of plastic bags.

The stepwise logistic regression results are presented in Table 5. The regional codes $3(p=0.014)$ and $5(p=0.014)$ which refer to Latin America and Caribbean and North America, respectively, resulted in a significant negative correlation to the acceptance of a single-use plastic bag.

\section{Discussion About Experiment 1}

Overall, findings indicate any intervention (sign and/or asking) is more effective than none. Any sign regardless of framing, coupled with asking customers if they want a bag, can be an effective and low-cost way to reduce plastic bag use. Interestingly, no significant difference in plastic bag refusal was observed between the positive and negative framing treatments. The human interaction of asking whether a customer needs a plastic bag is particularly important when there is no sign. A sign may also serve as a reminder to the clerk to ask each customer if they need a bag.

Regarding survey results, a large majority of respondents agreed plastic pollution is observable, a problem, and they could do something about it. Nevertheless, our findings confirm that a knowledge-action and intention-action gap exists (Hines et al., 1987). This reiterates the need for more studies to report on observed behavior rather than to draw conclusions about real behavior based on knowledge, attitudes, and behavioral intentions (Nelson et al., 2020). Many reasons may explain this. For example, tourists may have scarce knowledge of the fate of plastic wastes on Gili Trawangan. Also, in the short moment when the decision is made whether to take a bag or not during the purchasing process, other social, cultural or interpersonal factors associated with communication, exchange or the normalization of transaction behavior may have influenced the choice. The choice also had to be made quickly, as the sign intervention was placed at the counter. Perhaps if the sign was placed in the entrance, or at various locations around the shop, the customer would have more time to be primed about the issue and think about the decision during the purchasing process. Other aspects can only be speculated, but could be considered in future research such as how far the subjects need to carry the

TABLE 4 | Survey results about plastic pollution on Gili Trawangan.

\begin{tabular}{|c|c|c|c|}
\hline Survey statement & Agree (\%) & Disagree (\%) & No answer (\%) \\
\hline During my stay on Gili Trawangan I observed plastic pollution & 88.56 & 9.95 & 1.49 \\
\hline Plastic pollution is a problem on Gili Trawangan & 89.05 & 10.45 & 0.50 \\
\hline Plastic pollution on Gili Trawangan concerns me because of the environmental consequences & 94.53 & 4.47 & 1.00 \\
\hline Marine plastic pollution is a danger for both marine wildlife and humans & 98.01 & 1.49 & 1.00 \\
\hline My stay on Gili Trawangan contributes to plastic pollution & 65.67 & 33.33 & 1.00 \\
\hline I can do something against plastic pollution on Gili Trawangan & 93.53 & 4.47 & 1.00 \\
\hline
\end{tabular}


TABLE 5 | Regression results for accepted plastic bags (survey data).

Europe and Central Asia

Latin America and Caribbean

Middle East and North Africa

North America

South Asia

Sub-Saharan Africa

East Asia and Pacific Islands

Family income status

Accommodation cost class

Plastic pollution is a problem

Concern about plastic pollution

Marine plastic pollution is a danger

Tourists have a potential to mitigate plastic pollution

Sum of pro-environmental behavior on Gili Trawangan

Pseudo R-squared (Mc Fadden)

No. observations

Standard errors are reported in parentheses.

*, **, *** indicates significance levels at the $\mathrm{p}<0.05,0.01$, and 0.001 levels, respectively.

items or the state of intoxication of the subject (e.g., many tourists on the island consume alcohol).

The high significance of the sum of pro-environmental activities reveals an important factor. The more people already behave environmentally-friendly (i.e., refuse straws, avoid reef touching, use waste bins), the higher the likelihood is that they will perform other environmentally-friendly actions, such as refusing a plastic bag. Although the previous environmentallyfriendly actions were self-reported, this finding is in line with other research revealing a positive spill-over effect from one sustainable behavior to multiple others (Berger, 1997; Barnes et al., 2014).

Interestingly, the more money people spent on their accommodation, the more likely they were to accept a singleuse plastic bag. As the family's income status did not reveal any significant differences between observations, and was, thus, eliminated from the regression model, this factor does not correlate directly to the individual's economic situation, but rather to the importance of luxury and or convenience while on holiday. This may also be reflected in the use of plastic bags as they are an item of convenience.

Attributing relevance to the lower likelihood of refusing bags based on the consumer's region of origin being Latin America/ Caribbean and North America compared to those from East Asia/ Pacific Islands should be carefully interpreted given the uneven distribution of the number of observations per world region (both regions were only represented by a small sample size $\mathrm{n}=11$ and $\mathrm{n}=16$, respectively). Nevertheless, cultural differences in the effectiveness of differently framed messages (Uskul et al., 2009) as well as differences in concern about environmental issues have been previously reported (Gifford and Nilsson, 2014). There may also be various vacation effects. When tourists are away from their home countries and cultural contexts influencing their day-to-day behavior, the norms typically guiding their behavior may be altered or left behind on vacation. Additionally, because tourists are only there for a short time, they do not have to personally bear the costs of mismanagement or environmental degradation from their behavior in the long-term. Furthermore, vacation is typically a time for relaxing, and the convenience of taking a bag may not be viewed as a substantial negative action from the perspective of an individual who, in their eyes, is only more likely to do it on vacation.

\section{EXPERIMENT 2: SNORKELING INTERVENTION}

Coral reefs provide important public goods and ecosystem services worldwide, but are increasingly impacted by people through climate change induced coral bleaching, pollution and overuse from fishing and tourism (Hughes et al., 2003; Wilkinson, 2000). Declines in coral reef health and biodiversity have been linked to the diving industry and snorkeling (Schleyer and Tomalin, 2000; Uyarra et al., 2009). Pre-trip briefings are a common behavioral intervention to minimize diver impacts by reminding divers to be cautious shortly before entering the water. A growing body of literature suggests that snorkelers and divers who experience a pre-trip briefing, cause less impacts and damage (Camp and Fraser, 2012; Krieger and Chadwick, 2013; Hammerton and Bucher, 2015; Webler and Jakubowski, 2016).

However, different framings of the briefing message, and how their effectiveness may differ, have not been previously tested. For example, if whether highlighting "what to do" (e.g., always keep $2 \mathrm{~m}$ distance) vs. "what to avoid doing" (e.g., do not touch marine life) leads to fewer impacts. The following experiment tests the variation in effectiveness of different pre-trip briefing framings on a random sample of snorkelers on Gili Trawangan.

\section{Methods}

The study location was the northeast beach of Gili Trawangan commonly known as "Turtle Point." Various signs indicate the location of the area where turtles can be observed on a regular basis and snorkeling gear can be rented on multiple stands along the beach. This site was chosen because most interactions between snorkelers and turtles occur here (informal interviews with Gili Eco Trust staff and local dive businesses), it is the most frequented snorkel area around Gili Trawangan accessible from land, and, consequently, receives the most reef damage by snorkelers (Hampton and Hampton 2008).

The experiment comprises two treatments and a control setting. The medium for this experiment was a printed briefing sheet informing snorkelers about either a positive (careful) or negative (damaging) snorkeling behavior (see Table 6). This information sheet was shown to the subjects on a one-to-one basis (procedure explained below). After the interaction, the subjects were anonymously observed (by another researcher) while snorkeling for a period of $10 \mathrm{~min}$. Under the control setting, snorkelers were observed without prior interaction or intervention. The sampling times were fixed in the afternoon from 1:00 pm onwards, but slightly adjusted depending on the weather conditions. To minimalize confusion during the sampling only one of the treatments or control were implemented on each single day. To randomize the observation days, random assignment was done by using the 
TABLE 6 | Briefing sheets with four key notes highlighting positive (careful) snorkeling behavior (left) and negative (damaging) snorkeling behavior (right).

\section{Positive framing}

Save the reef

How to be a good guest in the underwater world

You can help life underwater stay colorful and beautiful by keeping your hands to yourself and your feet off the ground as much as possible to avoid touching the reef, turtles and other marine wildlife

As a good snorkeler you are always aware of where your fins and other equipment (camera, etc.) are to avoid involuntary contacts

Good snorkeler behavior means you keep at least $1.5 \mathrm{~m}$ distance to turtles at all times to ensure they remain calm in their environment and can surface to breathe. Good snorkelers enjoy watching the natural behavior of turtles and if it swims away, let it go! Take your plastic trash with you and earn extra karma by picking up more. You improve the marine animals' chances for survival and reproduction

\section{Negative framing}

Don't harm the ree

How to minimize your negative impact underwater

Your presence on the reef can have disastrous outcomes for the reef in the long-run if you touch or step on the reef, the turtles and other marine wildlife

If you are not aware of the position of your fins and other equipment (camera, etc.) you may contact the coral reef and injure it

Bad snorkeler behavior is when you get too close to turtles (less than $1.5 \mathrm{~m}$ ) and they become distressed and cannot surface to breathe. Don't chase them when they swim away!

Plastic trash is a hazard to marine wildlife. It decreases their chances of survival and successful reproduction. Pick it up! function sort() and order() in R Studio. The sample size per treatment and control was first set to 50. Each sampling day a minimum of 10 snorkelers were supposed to be observed. After the implementation of roughly 30 subjects per treatment and control, the effect size was calculated (Cohen's $d=0.71$ ), and the sample size was adjusted to 60 per treatment and control. In total, interventions and observations took place on 18 days between December 26, 2018 and January 20, 2018.

Snorkelers who were preparing to get into the water were approached by one of the volunteers of the local NGO Gili Eco Trust. The volunteers introduced themselves as volunteers, briefly outlined the work of the NGO (being coral reef conservation and waste treatment) and then provided information about snorkeling behavior to reduce impacts on the reef.

Following this interaction, and allowing for time for the subjects to adjust their gear and become comfortable in the water, the underwater observer watched the snorkeler(s) for $10 \mathrm{~min}$. Gender, use of snorkel, fins, camera and other equipment as well as the number of people surrounding the individual snorkeler $(>2 \mathrm{~m}$ distance to subject) during the 10-minute observation were noted. The position in the water was recorded every $60 \mathrm{~s}$ as the average position over the 10-minute period can act as a proxy for the snorkelers' level of experience. The snorkelers' proximity to the reef was also assessed every $60 \mathrm{~s}$ given the obvious correlation between reef proximity and contact. Several different kinds of impacts on the reef and marine life were observed, including type of contact (kick, touch, stand, etc.), type of coral (branching, foliaceous, massive, soft, table) or sponge, body part/ equipment (foot, hand, leg, fin, camera), type of impact (sediment suspension, single abrasion, multiple abrasion, breakage), voluntary vs. involuntary impact (voluntary included standing on the reef and grabbing the reef as opposed to accidental brushing against the reef and accidental fin kicks), coming closer than $1.5 \mathrm{~m}$ distance to a turtle, touching, obstructing and feeding (see Appendix II). When the 10-min observation was finished, the observer signaled to the volunteer on the beach that she was done and ready for the next observation. Consequently, the volunteer either indicated who she had informed already or approached a new snorkeler.

During data analysis, the number of impacts was included, as well as, a calculated impact score which was created to account for the different severity of impacts on marine wildlife. These were calculated by the type of impact with the coral reef (sediment suspension $=1$, single abrasion $=2$, multiple abrasion $=3$, breakage $=4$ ), the type of impact with a turtle (chasing, distance closer than $1.5 \mathrm{~m}$, obstructing $=2$, touching $/$ feeding $=$ 4) and the intention of the subject (impact was voluntary $=1$, impact was involuntary $=0$ ). For subjects with multiple impacts, the scores of each impact were summed up. With the ten observations of the subject's proximity to the reef, a median was calculated. A position index was created to use as a proxy for one's level of experience and comfortability snorkeling. For this, the observation every $60 \mathrm{~s}$ was assigned to a number (standing on the reef $=1$, standing on sand $=2$, swimming vertically $=3$, floating on the water surface $=4$, swimming horizontally $=5$, diving down $=6$ ) and the ten observations were averaged.

\section{Results of Experiment 2}

In total, 184 snorkelers were observed. As one of the observed snorkelers noticed that he was observed, this subject was removed from analysis, leaving 183 observations for data analysis. Overall, 144 impacts on marine wildlife by 73 snorkelers were noted, of which 28 impacts were involuntary. Impacts included standing and walking on the reef, touching the reef, breaking/kicking corals, suspension of sand close to corals, coming closer than $1.5 \mathrm{~m}$ to sea turtles, obstructing, chasing, and touching sea turtles. Although the Gili Eco Trust staff had reported feeding of turtles by snorkelers, this was not observed during the sampling days. The mean number of impacts per snorkeler is highest with $1.34 \pm$ 1.76 per 10 -minute observation period in the control setting. In the positive $(0.39 \pm 0.78)$ as well as in the negative framing $(0.62 \pm$ $1.03)$, the mean number of impacts was lower. The mean position index is $4.17 \pm 0.50$. The number of impacts is not normally distributed, and the variances are not homogeneous (all: $p<$ 0.001), thus, the non-parametric Kruskal Wallis Rank Sum test was run. There are highly significant differences between the treatments and control $(p<0.001)$ regarding the number of impacts a snorkeler had on the marine environment. These significant differences occur between the control and the positive treatment $(p<0.001)$ and between the control and the negative treatment $(p=0.013)$. There is no significant difference $(p=0.244)$ between the framed treatments (positive and negative). 


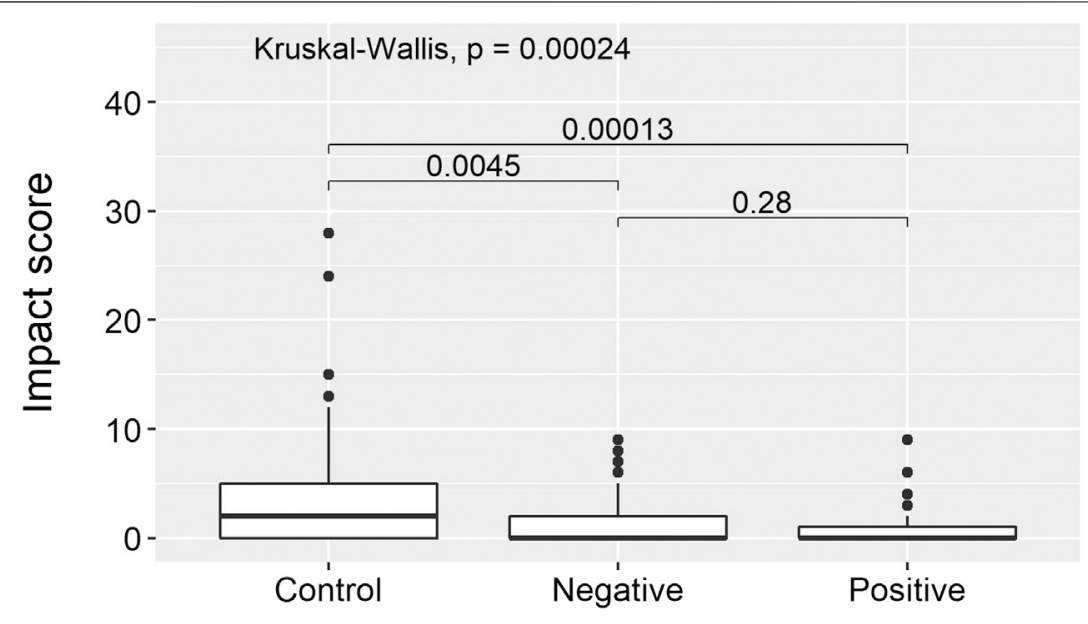

FIGURE 4 | The calculated impact score per treatment including the $p$-value resulting from the Kruskal-Wallis Rank Sum test and the $p$-values of Pair-wize Comparison Wilcoxon Rank Sum test. Boxes represent the interquartile range which contain $50 \%$ of the values. A line across the box indicates the median and filled circles are the outliers.

Concerning the weighted impact score, similar results were found. The mean impact score is highest in the control $(3.69 \pm$ $5.47)$, and lower in the positive $(0.97 \pm 2.07)$ and the negative treatment $(1.42 \pm 2.44)$. Likewise, the impact scores are not normally distributed, and the variances are not homogeneous (all: $p<0.001$ ). Significant differences between the treatments were detected $(p<0.001)$ and the post-hoc test revealed that these differences occur, again, between the control and the positive treatment $(p<0.001)$ and between the control and the negative treatment $(p=0.005)$. In between the framed treatments there is no significant difference $(p=0.280)$ (see Figure 4).

Regarding the Zero-inflated Poisson (ZIP) regression with the number of impacts and the Zero-inflated negative-binomial (ZINB) regression with the impact score, both indicate that the treatments, as well as a higher position index, are significantly negatively related with the number of impacts and the impact score (see Table 7). In the model with the number of impacts as the response variable, the factor "male" is significant. Concerning the logistic part of both models, the likelihood of obtaining a zero for the number of impacts, or for the impact score, increases with an increasing distance from the reef.
As the regression results reveal, neither the use of a camera, a life vest, fins or the tide and current had significant effects on the number of impacts or the impact score, as these variables were eliminated from the model due to insignificance.

\section{DISCUSSION OF EXPERIMENT 2}

The impact of snorkel related damages on the coral reef at "Turtle Point" was already reported in 1997 (Hampton and Hampton, 2008). The impacts observed in this survey included standing and walking on the reef, touching the reef, breaking/kicking corals, suspension of sediment close to corals, coming closer than $1.5 \mathrm{~m}$ to sea turtles, obstructing, chasing and touching sea turtles. Both, the analysis on the number of impacts as well as the calculated impact score produced similar results: The briefing sheet highlighting positive (careful) snorkeling behavior resulted in the least number of impacts and lowest impact scores. Both the positive and the negative briefings had a significant effect on mitigating damaging snorkeling behavior compared to the control. This was also confirmed by the zero-inflated Poisson (ZIP) regression of the number of impacts, as well as the zeroinflated Negative Binomial (ZINB) regression of the impact score.

TABLE 7 | Regression results for number of impacts (ZIP) and impact score (ZINB).

Count model with number of impacts

Negative treatment

Positive treatment

Position index

Sex: male

Median proximity to reef

$-0.544^{*}(0.219)$
$-0.798^{* \star}(0.251)$
$-0.927^{\star \star \star}(0.146)$
$0.374^{*}(0.182)$
Logistic model with number of impacts
$1.953^{\star \star \star}(0.461)$

$-0.544 *(0.219)$

-0.798 ** $(0.251)$

$-0.927^{\star \star *}(0.146)$

$1.953^{\star \star *}(0.461)$
Count model with impact score

$-0.527^{\star \star}(0.188)$

$-0.720^{\star \star \star}(0.207)$

$-0.783^{\star \star \star}(0.129)$

Logistic model with impact score $1.718^{\star \star \star}(0.332)$

Standard errors are reported in parentheses.

${ }^{*},{ }^{* *},{ }^{* * *}$ indicates significance levels at the $\mathrm{p}<0.05,0.01$, and 0.001 levels, respectively. 
Nevertheless, a framing effect could not be discovered as the differences between the positive and the negative treatment were insignificant, although indicating a trend toward the positive framing, similar to experiment 1 above.

A gender effect was revealed by the ZIP of the number of impacts. Men were more likely to have a higher number of impacts compared to women. This effect was also detected by a study that had exposed snorkelers to a pre-trip media-based intervention in Puerto Rico (Webler and Jakubowski, 2016). A reason for this effect may originate from the finding that women had a higher tendency to follow instructions from skill-briefings prior to diving (Hannak et al., 2011). This is also consistent with other studies that compare environmental attitudes and behaviors between male and female recreationists. Men are more likely to take risks and are less likely to follow pre-dive instructions (Vredenburgh and Cohen, 1993). As a result, compared to men, women are less damaging in general to the marine environment while snorkeling.

The position index can be used as a proxy for the subject's snorkel experience. Individuals that stand on the reef or sand for long time periods during their snorkel trip may feel uncomfortable swimming with snorkel and mask which indicates that they might be beginners. This highly correlates with the number of impacts and the impact score. The lower a subject's position index, the higher the number of impacts on the marine environment.

As expected, the median proximity to the coral reef correlates with the probability of impact. This is rather unsurprizing given that the closer the proximity, the higher the probability of impact. Subsequently, the designation of snorkel areas that are easily accessible without close contact to the reef, thus, sandy entry areas and deeper reefs, would make direct damaging impacts of snorkelers less likely. For this site, clear instructions on where and how to enter and exit the water without contacting the reef would likely decrease the probability of damaging impacts. The effect of the personal interaction would have to be considered as influential, as other studies have shown observed behavior change differences between mediums where the same message was conveyed. For example, having a real person convey the message has been shown to be more effective than just a sign. Nonetheless, a sign whether positive or negative, can very likely be an effective low-cost management tool.

\section{OVERALL CONCLUSION}

Overall, the findings of these two experiments are difficult to directly compare. However, they provide important and congruent insights on the effectiveness of informational messaging as an effective way to nudge pro-environmental behavior. They also both show that there are only small differences between positively and negatively framed informational messages. Both messages are effective as interventions, with both experiments indicating a trend toward a positive framing being slightly more effective but not statistically different. Future research could examine similar interventions, to confirm their effectiveness in other contexts.
From a policy perspective, the most important conclusions from this study would be to have any nudging intervention rather than none, regardless of the negative or positive framing. However, our understanding of this may differ across contexts with further studies in the future.

It is clear from this study that informational messaging strategies can be implemented as effective management tools to reduce harmful environmental behavior at the individual level. A key reflection is that the interventions tested here are very low cost and easy-to-implement. These results have broader practical applications for encouraging pro-environmental behavior, particularly in situations where there is already a human interaction (i.e., entrance to a park, check-out counter, transportation, rental equipment, etc.). Regarding the situation in a grocery store, asking whether a customer needs a bag is effective in reducing the number of plastic bags used and, consequently, this should be implemented to decrease the consumption of single-use plastic bags where necessary.

Concerning snorkel tourism, we show that pre-trip briefings can be very effective. We suggest implementing a briefing upon rental of snorkel gear, or before entering the water during regular SCUBA dive briefings. Due to the finding that impacts are highest from beginners, an introductory lesson would be helpful to improve snorkeling skills of novices. In the case of Gili Trawangan, information sheets could be offered to rental stall owners and require mandatory reading of the briefing sheet before renting the equipment. Likewise, snorkel and SCUBA boat tour operators could present a briefing sheet before snorkelers enter the ocean.

Reflecting broadly, understanding how and why human behavior changes, or not, is essential for effective environmental conservation and management (Cinner, 2018). More generally, as noted by Reddy et al. (2017), behavioral sciences are a "largely untapped resource for conservation," (p. 248). This is now changing, spurred by a growing literature on 'nudging' as a conceptual framing about how to use simple interventions to guide behavior toward more desirable social and environmental outcomes, popularized by the book Nudge (Thaler and Sunstein, 2008). Nudging interventions, particularly through framed informational messaging, are an undervalued low-cost and non-invasive approach for helping achieve more pro-environmental behavior. Tourism is a sector with a large untapped potential to utilize these types of approaches to reduce its local impacts. While it may be difficult to fundamentally change human behavioral tendencies on vacation, nudging approaches don't require these large systemic changes. Although larger systemic changes in the tourism sector such as travel and consumptions practices are likely to solve issues in the long term, non-invasive nudges provide workable and quick solutions in the short term.

From a research perspective, and specifically in the environmental context, more experiments with real observed behavior are needed to test the effectiveness of the many proposed interventions, mediums for implementation and framings that have been suggested (Yoeli et al., 2017; Spranz et al., 2018; Nelson et al., 2019; Rare, 2019). Finally, one of the most well supported findings in the environmental and human 
behavior literature is the existence of the knowledge-action and intention-action gaps. While both studies in this paper confirm this gap, they also provide robust data on low-cost and easily implementable nudging interventions to help close those gaps in practice.

\section{DATA AVAILABILITY STATEMENT}

The raw data supporting the conclusions of this article will be made available by the authors, without undue reservation.

\section{ETHICS STATEMENT}

The studies involving human participants were reviewed and approved by Ethics Review Board of Leibniz Centre for Tropical Marine Research: Marion Glaser and Agostino Merico. Written informed consent for participation was not required for this study in accordance with the national legislation and the institutional requirements.

\section{AUTHOR CONTRIBUTIONS}

Conceptualization, $\mathrm{KN}$; methodology, $\mathrm{KN}$; validation, $\mathrm{MB}$; formal analysis, $\mathrm{MB}$; investigation, $\mathrm{MB}$ and $\mathrm{KN}$; resources, $\mathrm{KN}$

\section{REFERENCES}

Ahn, S. J.-G., Fox, J., Dale, K. R., and Avant, J. A. (2015). Framing virtual experiences: effects on environmental efficacy and behavior over time. Commun. Res. 42 (6), 839-863. doi:10.1177/0093650214534973

Avineri, E., and Waygood, E. O. D. (2013). Applying valence framing to enhance the effect of information on transport-related carbon dioxide emissions. Transport. Res. Pol. Pract. 48, 31-38. doi:10.1016/j.tra.2012. 10.003

Bachtiar, I. (2000). Community based coral reef management of the marine tourism park Gili Indah, Lombok Barat. Komunitas 3 (1), 67-77.

Barker, N. H. L., and Roberts, C. M. (2004). Scuba diver behaviour and the management of diving impacts on coral reefs. Biol. Conserv. 120 (4), 481-489. doi:10.1016/j.biocon.2004.03.021

Barnes, H., Carrico, A. R., Weber, E. U., Toner, K., and Vandenbergh, M. P. (2014). Positive and negative spillover of pro-environmental behavior: an integrative review and theoretical framework. Global Environ. Change 29, 127-138. doi:10. 1016/j.gloenvcha.2014.09.004

Baxter, J., and Gram-Hanssen, I. (2016). Environmental message framing: enhancing consumer recycling of mobile phones. Resour. Conserv. Recycl 109, 96-101. doi:10.1016/j.resconrec.2016.02.012

Berger, I. E. (1997). The demographics of recycling and the structure of environmental behavior. Environ. Behav. 29 (4), 515-531. doi:10.1177/ 001391659702900404

Brouwer, R., Hadzhiyska, D., Ioakeimidis, C., and Ouderdorp, H. (2017). The social costs of marine litter along European coasts. Ocean Coast Manag. 138, 38-49. doi:10.1016/j.ocecoaman.2017.01.011

Burn, S. (1991). Social psychology and the stimulation of recycling behaviors: the block leader approach. J. Appl. Soc. Psychol. 21 (8), 611-629. doi:10.1111/j.15591816.1991.tb00539.x

Camp, E., and Fraser, D. (2012). Influence of conservation education dive briefings as a management tool on the timing and nature of recreational SCUBA diving impacts on coral reefs. Ocean Coast Manag. 61, 30-37. doi:10.1016/j. ocecoaman.2012.02.002 and SP; data curation, MB; writing-original draft preparation, $\mathrm{MB}$ and $\mathrm{KN}$; writing-review and editing, $\mathrm{KN}, \mathrm{MB}$, and $\mathrm{SP}$; visualization, $\mathrm{MB}$; supervision, $\mathrm{KN}$ and $\mathrm{SP}$; funding acquisition, $\mathrm{KN}, \mathrm{SP}$, and MB. All authors have read and agreed to the published version of the manuscript.

\section{FUNDING}

This study was funded by a Rapid Ocean Conservation (ROC) grant from the Waitt Foundation. Open access fees are paid by the Leibniz Centre for Tropical Marine Research (ZMT).

\section{ACKNOWLEDGMENTS}

The authors would like to thank Delphine Robbe, Sian Williams and interns at the Gili EcoTrust for assisting with this research. We send extended thanks to local residents, staff and owners of the many businesses on the Gili Islands for their generosity, hospitality and willingness to participate in this study. We also thank Achim Schlüter for discussions and comments on earlier drafts of the manuscript. The development of this paper was additionally supported by the European Cooperation in Science and Technology (COST) action network on Ocean Governance, and the Land-Sea interactions working group in particular.

Cannucciari, P., and Martiana, N. (2016). Validation of critical issues in the waste value chain and designing actions for implementation with focus on Gili Trawangan, the western part of Lombok and Mataram. Report for GIZ Sustainable Regional Economic Growth and Investment Programme (SREGIP). Available at: https://panorama.solutions/sites/default/files/final_ report_30.06.16_gilit_only.pdf.

Cheng, B. Y. T., Woon, D. K., and Lynes, J. K. (2011). The use of message framing in the promotion of environmental sustainability behaviors. Soc. Market. Q 17 (2), 48-62. doi:10.1080/15245004.2011.570859

Cinner, J. (2018). How behavioral science can help conservation. Science 362, 889-891. doi:10.1126/science.aau6028

Colding, J., and Barthel, S. (2019). Exploring the social-ecological systems discourse 20 years later. Ecol. Soc. 24 (1). doi:10.5751/ES-10598-240102

Cook, S. W., and Berrenberg, J. L. (1981). Approaches to encouraging conservation behavior: a review and conceptual framework. J. Soc. Issues 37 (2), 73-107. doi:10.1111/j.1540-4560.1981.tb02627

Dwyer, W. O., Leeming, F. C., Cobern, M. K., Porter, B. E., and Jackson, J. M. (1993). Critical review of behavioral interventions to preserve the environment: research since 1980. Environ. Behav. 25 (5), 275-321. doi:10.1177/ 0013916593255001

Entman, R. M. (1993). Framing: toward clarification of a fractured paradigm. J. Commun. 43 (4), 51-58. doi:10.1111/j.1460-2466.1993.tb01304.x

Entman, R. M., Matthes, J., and Pellicano, L. (2009). "Nature, sources, and effects of news framing," in The handbook of journalism studies, (Abingdon, United Kingdom: Routledge) 175-190.

Gifford, R., and Nilsson, A. (2014). Personal and social factors that influence proenvironmental concern and behaviour: a review. Int. J. Psychol. 49 (3), 141-157. doi:10.1002/ijop.12034

Graci, S. R. (2013). Collaboration and partnership development for sustainable tourism. Tourism Geogr 15 (1), 25-42. doi:10.1080/14616688.2012.675513

Halim, H. S. (2017). Scrutinizing coastal ecotourism in Gili Trawangan, Indonesia. Int. J. Mar. Sci 7 (25), 247-259. doi:10.5376/ijms.2017.07.0025

Hammerton, Z., and Bucher, D. (2015). Levels of intervention-reducing SCUBAdiver impact within subtropical marine protected areas. J. Ecotourism 14 (1), 3-20. doi:10.1080/14724049.2015.1073738 
Hampton, M. P., and Hampton, J. (2008). "Is the beach party over? Tourism and the environment in small islands: a case study of Gili Trawangan, Lombok, Indonesia," in Tourism in Southeast Asia: challenges and new directions, (Copenhagen, Denmark: NIAS Press) 286-308.

Hannak, J. S., Kompatscher, S., Stachowitsch, M., and Herler, J. (2011). Snorkeling and trampling in shallow-water fringing reefs: risk assessment and proposed management strategy. J. Environ. Manag. 92 (10), 2723-2733. doi:10.1016/j. jenvman.2011.06.012

Heimlich, J. E., and Ardoin, N. M. (2008). Understanding behaviour to understand behaviour change: a literature review. Environ. Educ. Res. 14 (3), 215-237. doi:10.1080/13504620802148881

Hines, J. M., Hungerford, H. R., and Tomera, A. N. (1987). Analysis and synthesis of research on responsible environmental behavior: a meta-analysis. J. Environ. Educ. 18 (2), 1-8. doi:10.1080/00958964.1987.9943482

Hughes, T. P., Baird, A. H., Bellwood, D. R., Card, M., Connolly, S. R., Folke, C., et al. (2003). Climate change, human impacts, and the resilience of coral reefs. Science 301 (5635), 929-933. doi:10.1126/science.1085046

Jambeck, J. R., Geyer, R., Wilcox, C., Siegler, T. R., Perryman, M., Andrady, A., et al. (2015). Plastic waste inputs from land into the ocean. Science 347 (6223), 768-771. doi:10.1126/science.1260352

Kahneman, D., and Tversky, A. (1979). Prospect theory. Econometrica 47 (2), 311. doi: $10.2307 / 3791683$

Kennedy, E. H., Beckley, T. M., McFarlane, B. L., and Nadeau, S. (2009). Why we don't "walk the talk": understanding the environmental values/behaviour gap in Canada. Hum. Ecol. Rev. 16 (2), 151-160.

Kim, S. B., and Kim, D. Y. (2014). The effects of message framing and source credibility on green messages in hotels. Cornell Hospitality Quarterly 55 (1), 64-75. doi:10.1177/1938965513503400

Kim, S. S., Nguyen, P. H., Yohannes, Y., Abebe, Y., Tharaney, M., Drummond, E., et al. (2019). Behavior change interventions delivered through interpersonal communication, agricultural activities, community mobilization, and mass media increase complementary feeding practices and reduce child stunting in Ethiopia. J. Nutr. 149 (8), 1470-1481. doi:10.1093/jn/nxz087

Kollmuss, A., and Agyeman, J. (2002). Mind the gap: why do people behave environmentally and what are the barriers to pro-environmental behaviour. Environ. Educ. Res. 8 (3), 239-260. doi:10.1080/1350462022014540

Krieger, J. R., and Chadwick, N. E. (2013). Recreational diving impacts and the use of pre-dive briefings as a management strategy on Florida coral reefs. J. Coast Conserv. 17 (1), 179-189. doi:10.1007/s11852-012-0229-9

Levin, I., Schneider, S., and Gaeth, G. (1998). All frames are not created equal: a typology of framing effects. Organ. Behav. Hum. Decis. Process 76 (2), 149-188. doi:10.1006/obhd.1998.2804

Levitt, S. D., and List, J. A. (2007). What do laboratory experiments measuring social preferences reveal about the real world?. J. Econ. Perspect 21 (7), 153-174. doi:10.1257/jep.21.2.153

Maibach, E. W., Nisbet, M., Baldwin, P., Akerlof, K., and Diao, G. (2014). Reframing climate change as a public health issue in the United States. Int. J. Clim. Chang. Strategies Manag. 10 (1), 299. doi:10.1108/ijccsm.2011. 41403bag.001

Masud, M. M., Akhtar, R., Afroz, R., Al-Amin, A. Q., and Kari, F. B. (2015). Proenvironmental behavior and public understanding of climate change. Mitig. Adapt. Strategies Glob. Change 20 (4), 591-600. doi:10.1007/s11027-013-9509-4

McKenzie-Mohr, D. (2000). Promoting sustainable behavior: an introduction to community-based social marketing. J. Soc. Issues 56 (3), 543-554. doi:10.1111/ 0022-4537.00183

Morrow, K. M., Paul, V. J., Liles, M. R., and Chadwick, N. E. (2011). Allelochemicals produced by caribbean macroalgae and cyanobacteria have species-specific effects on reef coral microorganisms. Coral Reefs. 30 (2), 309-320. doi:10.1007/s00338-011-0747-1

Nelson, K. M., Anggraini, E., and Schlüter, A. (2020). Virtual reality as a tool for environmental conservation and fundraising. PloS One 15 (4), e0223631. doi:10. 1371/journal.pone. 0223631

Nelson, K. M., Partelow, S., and Schlüter, A. (2019). Nudging tourists to donate for conservation: experimental evidence on soliciting voluntary contributions for coastal management. J. Environ. Manag. 237, 30-43. doi:10.1016/j.jenvman. 2019.02 .003
Nolan, J. M., Schultz, P. W., Cialdini, R. B., Goldstein, N. J., and Griskevicius, V. (2008). Normative social influence is underdetected. Pers. Soc. Psychol. Bull 34 (7), 913-923. doi:10.1177/0146167208316691

Osbaldiston, R., and Schott, J. P. (2012). Environmental sustainability and behavioral science: meta-analysis of proenvironmental behavior experiments. Environ. Behav. 44 (2), 257-299. doi:10.1177/ 0013916511402673

Partelow, S., and Nelson, K. (2018). Social networks, collective action and the evolution of governance for sustainable tourism on the Gili Islands, Indonesia. Mar. Pol. 112, 2020. doi:10.1016/j.marpol.2018.08.004

PEMRG (2018). Global plastic production | Statista. Available at: https://wwwstatista-com.libproxy1.nus.edu.sg/statistics/282732/global-production-ofplastics-since-1950/ (Accessed December 2020).

Piñon, A., and Gambara, H. (2005). A meta-analytic review of framing effect: risky, attribute and goal framing. Psicothema 17 (2), 325-331. doi:10.1027/2151-2604/a000321

Plous, S. (1993). The psychology of judgement and decision making. New York, NY: Mcgraw-Hill Book Company.

Rare (2019). Behavior change for nature: a behavioral science toolkit for practitioners. Arlington, VA, USA: Rare.

Reddy, S. M. W., Montambault, J., Masuda, Y. J., Keenan, E., Butler, W., Fisher, J. R. B., et al. (2017). Advancing conservation by understanding and influencing human behavior. Conserv. Lett. 10, 248-256. doi:10.1111/conl.12252

Schleyer, M. H., and Tomalin, B. J. (2000). Damage on South African coral reefs and an assessment of their sustainable diving capacity using a fisheries approach. Bull. Mar. Sci. 67 (3), 1025-1042.

Schultz, P. W. (1999). Changing behavior with normative feedback interventions: a field experiment on curbside recycling. Basic Appl. Soc. Psychol. 21, 25-36. doi:10.1207/15324839951036533

Scott, D., Gössling, S., and Hall, C. M. (2012). International tourism and climate change. Wiley Interdiscip. Rev.: Clim. Change 3 (3), 213-232. doi:10.1002/wcc.165

Spence, A., and Pidgeon, N. (2010). Framing and communicating climate change: the effects of distance and outcome frame manipulations. Global Environ. Change 20 (4), 656-667. doi:10.1016/j.gloenvcha.2010.07.002

Spranz, R., Schlüter, A., and Vollan, B. (2018). Morals, money or the master: the adoption of eco-friendly reusable bags. Mar. Pol. 96, 270-277. doi:10.1016/j. marpol.2018.01.029

Steg, L., and Vlek, C. (2009). Encouraging pro-environmental behaviour: an integrative review and research agenda. J. Environ. Psychol. 29 (3), 309-317. doi:10.1016/j.jenvp.2008.10.004

Sunstein, C. R. (2014). Nudging: a very short guide. J. Consum. Pol. 37 (4), 583-588. doi:10.1007/s10603-014-9273-1

Thaler, R. H., and Sunstein, C. (2008). Nudge: improving Decisions About Health, Wealth, and Happiness. London, United Kingdom: Penguin Group.

Tversky, A., and Kahneman, D. (1992). Advances in prospect theory: cumulative representation of uncertainty. J. Risk Uncertain 5 (4), 297-323. doi:10.1007/ BF00122574

Uskul, A. K., Sherman, D. K., and Fitzgibbon, J. (2009). The cultural congruency effect: culture, regulatory focus, and the effectiveness of gain-vs. loss-framed health messages. J. Exp. Soc. Psychol. 45 (3), 535-541. doi:10.1016/j.jesp.2008. 12.005

Uyarra, M. C., Watkinson, A. R., and Côté, I. M. (2009). Managing dive tourism for the sustainable use of coral reefs: validating diver perceptions of attractive site features. Environ. Manag. 43 (1), 1-16. doi:10.1007/s00267008-9198-Z

Vigors, B. (2019). Citizens' and farmers' framing of 'positive animal welfare'and the implications for framing positive welfare in communication. Animals 9 (4), 147. doi:10.3390/ani9040147

Vos, A. De., Biggs, R., and Preiser, R. (2020). Methods for understanding socialecological systems: a review of place-based studies. Ecol. Soc. 24. doi:10.5751/ ES-11236-240416

Vredenburgh, A. G., and Cohen, H. H. (1993). Compliance with warnings in high risk recreational activities: skiing and scuba. Proc. Hum. Factors Ergon. Soc. Annu. Meet 37, 945-949. doi:10.1177/154193129303701403

Webler, T., and Jakubowski, K. (2016). Mitigating damaging behaviors of snorkelers to coral reefs in Puerto Rico through a pre-trip media-based intervention. Biol. Conserv. 197, 223-228. doi:10.1016/j.biocon.2016. 03.012 
White, K., MacDonnell, R., and Dahl, D. W. (2011). It's the mind-set that matters: the role of construal level and message framing in influencing consumer efficacy and conservation behaviors. J. Market. Res. 48 (3), 472-485. doi:10.1509/jmkr.48.3.472 Wilkinson, C. (2000). Status of coral reefs of the world: 2000. Townsville, Australia: Australian Institute of Marine Sciences.

Willmott, L., and Graci, S. R. (2012). Solid waste management in small island destinations. Téoros Revue de Recherche En Tourisme 71, 71-76. doi:10.7202/ 1036566ar

Yoeli, E., Budescu, D. V., Carrico, A. R., Magali, A., Deshazo, J. R., Ferraro, P. J., et al. (2017). Behavioral science tools to strengthen energy and environmental policy. Behav. Sci. Pol. 3, 69-79. doi:10.1353/bsp.2017.0006
Conflict of Interest: The authors declare that the research was conducted in the absence of any commercial or financial relationships that could be construed as a potential conflict of interest.

Copyright (C) 2021 Nelson, Bauer and Partelow. This is an open-access article distributed under the terms of the Creative Commons Attribution License (CC $B Y)$. The use, distribution or reproduction in other forums is permitted, provided the original author(s) and the copyright owner(s) are credited and that the original publication in this journal is cited, in accordance with accepted academic practice. No use, distribution or reproduction is permitted which does not comply with these terms. 


\section{Table 8 |}

\section{Observation Scheme for Experiment 2.}

Date
Snorkel $(\mathrm{y} / \mathrm{n})$
Tide $(1 / \mathrm{m} / \mathrm{h})$

Minutely

observation

Position in water

Proximity to reef (in $\mathrm{m}$ )
$\operatorname{Sex}(f / m)$

Fins $(y / n)$

Current $(1 / \mathrm{m} / \mathrm{h})$
Camera $(y / n)$

Crowd

${ }^{*}$ standing on the reef $=1$, standing on sand $=2$, swimming vertically $=3$, floating on the water surface $=4$, swimming horizontally $=5$, diving down $=6$. 